\title{
RESTORATIVE FAILURE RATE AFTER DENTAL TREATMENT OF EARLY CHILDHOOD CARIES UNDER GENERAL ANESTHESIA Morsy $\mathbf{N}^{1} B D S$, Dowidar $\mathbf{K}^{2} P h D$, Bakry $\mathbf{N}^{2} P h D$.
}

\begin{abstract}
:
Introduction: Comprehensive dental care of early childhood caries (ECC) is often accomplished under general anesthesia (GA). General anesthesia allows dental treatment to be performed under optimal conditions thus ensuring an ideal outcome. Failures of restorations after dental rehabilitation will increase the risk for caries development. Few studies have been carried out to evaluate the restorative failure rate of dental treatment under GA among children with ECC.

Objective: To assess the failure rate of restorations for children with early childhood caries undergoing dental treatment under general anesthesia. Materials and methods: Dental records of healthy children diagnosed with early childhood caries (ECC), aged 3-6 years, and had dental treatment under general anesthesia were reviewed. Data regarding restorative failure was gathered from two groups of children according to recall period (group I after 6 months, and group II after 12 months).

Results: The highest failure rate in group I related was to composite restorations $(96.2 \%)$, followed by anterior glass ionomer (91.7\%), posterior glass ionomer $(20 \%)$, stainless steel crown (SSC) $(1 \%)$, and finally amalgam $(0 \%)$. In group II the highest failure rate was related to composite restorations $(88.5 \%)$, anterior GIC $(77.8 \%)$,posterior GIC $(28.6 \%)$, amalgam $(13 \%)$, and finally SSC $(5.6 \%)$.In composite restorations, fracture in both groups was the main cause of failure, group I (100.0\%), and group II (87.0\%), whereas, secondary caries was the second cause in group II $(13.0 \%)$. In group (I), no amalgam failure was recorded, while in group (II) secondary caries was the main cause of amalgam failure (67.0\%), followed by fracture (33.0\%). In both groups, fracture of restorations, and secondary caries were the main causes of anterior GIC failure (100.0\%),
\end{abstract} and posterior GIC failure (100.0\%). Loss of retention was the main cause of SSCs failure in both groups (100.0\%).

Conclusion: Anterior restorations have a higher failure rate than posterior restorations. Factors affecting restoration failure significantly were: Unsupervised tooth brushing, and failure to conform to recall appointments.

Key words: Early childhood caries, general anesthesia, restorative failure, primary teeth.

${ }^{1}$ Resident at the pediatric Dentistry Department, Faculty of Dentistry, Alexandria University, Alexandria, Egypt.

${ }^{2}$ Professor of pediatric dentistry, Faculty of Dentistry, Alexandria University, Alexandria, Egypt.

\section{INTRODUCTION}

General anesthesia (GA) is a medical procedure that renders the patient unconscious, allowing for the safe medical and dental diagnostic and surgically invasive procedures. Delivering dental treatment under GA can have significant positive effects on the quality of life for children and their families and can improve access to dental care. GA is an effective way to provide dental treatment for children who may be uncooperative, cognitively immature, highly anxious or fearful, have special needs, or medically-compromised and unable to receive treatment in a traditional office setting (1).

General anesthesia has several advantages as being safe, efficient, and convenient with less physical and mental stress for both the patient and the dentist. Extensive highquality treatment performed in a single visit, with minimal discomfort to the patient is one of GA's main benefits (2). Moreover it provides optimum conditions for restorative treatment such as maximum contamination control, immobilization of the patient and elimination of reflexes.

Early childhood caries (ECC) is one of the most common indications for treatment under general anesthesia (3-5). There are adverse effects of ECC on children, as oral pain and inability to eat or sleep, so it is necessary for comprehensive oral rehabilitation to improve quality of life of these children $(6,7)$.

A study by Sheehy et al. (8) on children diagnosed with ECC, after 6 months of treatment under GA, showed a decrease in sugar intake, and behavioral oral hygiene changes. Also, a study by Eidelman et al. (9) performed on children diagnosed with ECC, after 6-24 months of their rehabilitations under GA, showed that the quality of restorative treatment under GA was better than the quality of treatment performed under conscious sedation.

Holland et al. (10) demonstrated that the average survival time for an amalgam restoration in primary teeth was only 31 months, and that the age of the child at the time of placement was directly related to the longevity of the restoration. The younger the child is, the sooner the failure happens.

Despite this comprehensive dental treatment these children are likely to experience recurrence of caries, and high restorative failure rates (11). Treatment outcomes have been shown to be dependent upon procedures performed as well as materials utilized (12). Limited studies have been carried out to evaluate the clinical failure rate for dental treatment under GA among children treated by postgraduate students. Therefore the aim of this study was to investigate the failure rate of restorations after dental treatment under GA in healthy children diagnosed with early childhood caries treated by postgraduate students in a teaching hospital.

\section{MATERIALS AND METHODS}

All available records of healthy children who received dental treatment under GA at the Faculty of Dentistry, Alexandria University during 2013-2014, and at and at least 6 months had elapsed since their treatment were evaluated by the researcher. The children were treated by post graduate students using the following restorative materials (composite, amalgam, conventional GIC, SSCs). Patients were divided into two groups according to recall period (6 
months, and 12 months), each group consisted of the patients that fulfilled the inclusion criteria:

- Healthy children according to American Society of Anesthesiologists (ASA) I or II (13).

- Children diagnosed with (ECC) according to American Academy of Pediatric Dentistry (AAPD) (14).

- Children received dental treatment between 2013-2014.

- Children with complete records.

An informed consent was obtained from parents, or caregivers. A data-collecting chart was composed of a series of questions and the researcher performed the clinical examination.

Questionnaire: The examiner collected data through personal interview with parent. Information collected included the following: Demographic data, medical history, dental history including oral hygiene habits, dental visits, and dietary habits.

I. Clinical examination: Dental examination was conducted using a mirror and probe with good illumination. The researcher recorded information regarding restorative failure. Restorative failure included restorations that needed to be replaced due to fracture, dislodgment, abscess, or recurrence of caries. Intact restorations without new caries at the time of follow-up were considered successful (11). For ethical considerations, the researcher treated any tooth with restoration failure, or recurrence of caries.

Data were collected it was revised, coded and fed to statistical software SPSS IBM version 20. The graphs were constructed using Microsoft excel software. All statistical analysis were done using two tailed tests and alpha error of 0.05 . Failure rate was calculated by dividing the total number of restorations to be replaced by the total number of restorations per individual for anterior and posterior restorations. Multiple stepwise logistic regressions were used to determine automatically which variables to add or drop from the model, and identify the most important factors affecting anterior, and posterior restoration failure.

\section{RESULTS}

Records of 574 patients who had undergone dental treatment under GA in years 2013 and 2014 where reviewed. Eighty patients fulfilled the inclusion criteria and were recalled for dental check up, but only 50 returned for follow up. The age of the children that participated in the study ranged from 3-6 years with a mean age of 4.5 years.

Table (1) presents the distribution of gender and parental educational level among the study sample. The differences between both groups in mentioned categories were not significant ( $\mathrm{p}>0.05)$ except for gender there was a significant difference $(\mathrm{p}=0.027)$ between males and females, in group I (males $75 \%$, females $25 \%$ ), while in group II (males 44\%, females 56\%).

The patients that were recalled after 6 months (group I) showed the failure rates of composite, anterior and posterior glass ionomer, amalgam restorations and SSCs to be
$(96.2 \%, 91.7 \%, 20 \%, 0 \%, 1 \%)$ respectively as shown in figure (1).

Table (1): Distribution of gender and mothers' educational level of the study sample.

\begin{tabular}{|c|c|c|c|c|c|c|}
\hline \multirow{3}{*}{ Variable } & \multirow{3}{*}{ Category } & \multicolumn{4}{|c|}{ Recall Period } & \multirow{3}{*}{$\mathrm{MCI}$} \\
\hline & & \multicolumn{2}{|c|}{$\begin{array}{c}6 \text { months(group I) } \\
n=25\end{array}$} & \multicolumn{2}{|c|}{$\begin{array}{c}12 \text { month (group II) } \\
n=25\end{array}$} & \\
\hline & & $\mathrm{N}_{0}$ & $\%$ & No & $\%$ & \\
\hline \multirow{2}{*}{ Gender } & Male & 19 & 75.0 & 11 & 44.0 & \multirow{2}{*}{0.027} \\
\hline & Female & 6 & 25.0 & 14 & 56.0 & \\
\hline \multirow{3}{*}{ Mother education } & IIliterate & 12 & 48.0 & 15 & 60.0 & \multirow{3}{*}{0.445} \\
\hline & High school & 8 & 32.0 & 8 & 32.0 & \\
\hline & University grade & 5 & 20.0 & 2 & 8.0 & \\
\hline \multirow{3}{*}{ Father education } & Illiterate & 7 & 28.0 & 13 & 52.0 & \multirow{3}{*}{0.176} \\
\hline & High school & 13 & 52.0 & 10 & 40.0 & \\
\hline & University grade & 5 & 20.0 & 2 & 8.0 & \\
\hline
\end{tabular}

MCP: P value based on Mont Carlo exact probability $* P<0.05$ (significant)

Regarding oral hygiene habits, either after 6 or 12 months recall period, the majority of the children brushed their teeth once per day, in group I $(60 \%)$, while in group II $(48 \%)$. Tooth brushing when performed was done mainly by the parents, in group I $(76 \%)$, while in group II $(64 \%)$. It was also noticed that the majority of the children never visited the dentist after 6 or 12 months recall period (76\% and $72 \%$ respectively) as shown in table (2)

Table (2): Distribution of oral hygiene, and dental visits of the study sample

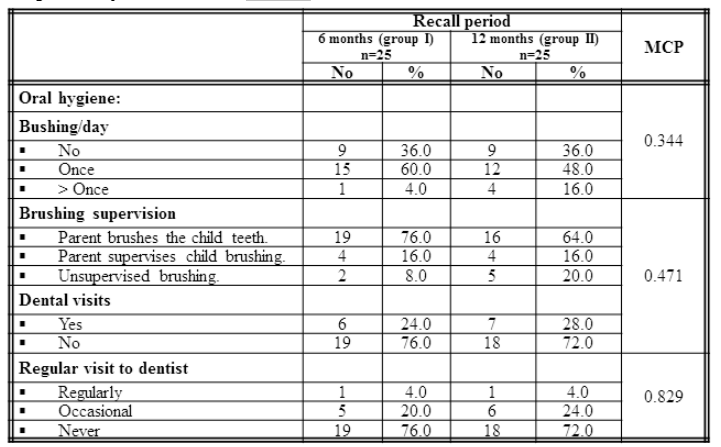

MCP: P value based on Mont Carlo exact probability.

${ }^{*} P<0.05$ (significant)

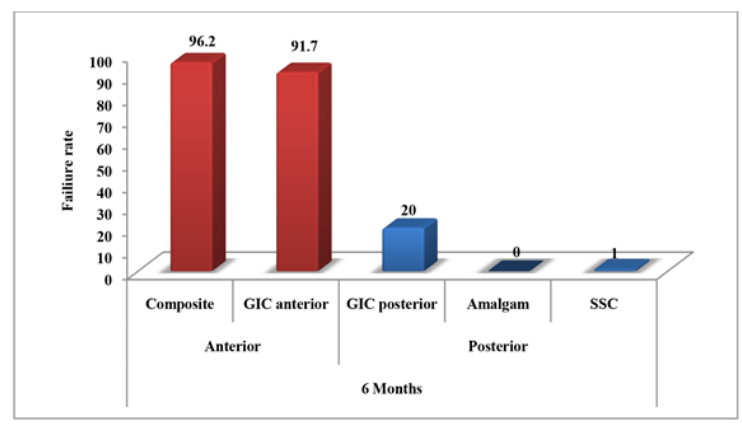

Fig (1): Failure rate of anterior and posterior restorations after 6 months recall period (group I). 
Differences between failure rates among anterior restorations were not significant $(\mathrm{P}>0.05)$, whereas failure rates between posterior restorations were significant $(\mathrm{P}=0.001)$. After 12 months recall period (group II), the failure rates of composites, anterior and posterior glass ionomers, amalgam restorations and SSCs to be $(88.5 \%$, $77.8 \%, \quad 28.6 \%, \quad 13 \%, \quad 5.6 \%$ ) respectively (figure 2 ). Differences between failure rates among anterior restorations were also not significant $(\mathrm{P}>0.05)$, where failure rates between posterior restorations were significant $(\mathrm{P}=0.05)$.

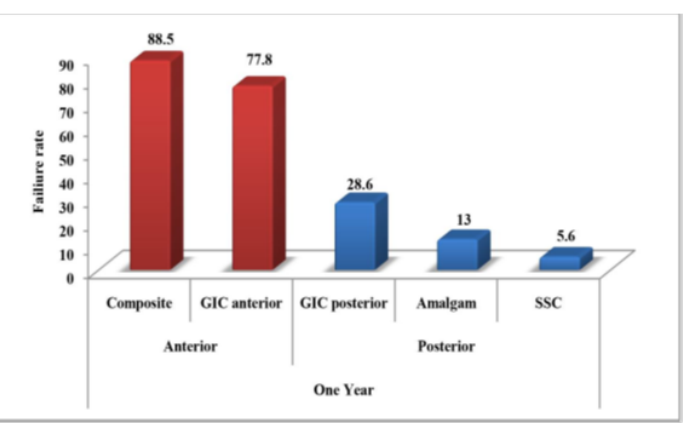

Fig (2): Failure rate of anterior and posterior restorations after 12 months recall period (group II).

Table (3) shows the failure rate of composite, anterior glass ionomer, posterior glass ionomer, amalgam and SSC as $(92.3 \%, 83.3 \%, 23.5 \%, 10 \%, 3.3 \%)$ respectively in the whole study period. The highest failure rate was composite restorations $(92.3 \%)$, while the lowest one was SSC (3.3\%). Differences between failure rates of anterior $(\mathrm{P}=0.307)$, and posterior restorations $(\mathrm{P}=0.059)$ for the whole study sample were not significant.

Table (3): Failure rates of restorations in the whole study period

\begin{tabular}{|c|c|c|c|c|c|c|}
\hline Recall period & Site & Restoration & Total & Intact & Failed & $\begin{array}{c}\text { Failur } \\
\text { e rate } \\
\%\end{array}$ \\
\hline \multirow{8}{*}{$\overline{\frac{\pi}{3}}$} & \multirow{2}{*}{ Anterior } & Composite & 52 & 4 & 48 & 92.3 \\
\hline & & Anterior GIC & 30 & 5 & 25 & 83.3 \\
\hline & FEP & & \multicolumn{4}{|c|}{0.307} \\
\hline & \multirow{3}{*}{ Posterior } & Posterior GIC & 17 & 13 & 4 & 23.5 \\
\hline & & Amalgam & 30 & 27 & 3 & 10 \\
\hline & & $\mathrm{SSC}$ & 209 & 202 & 7 & 3.3 \\
\hline & MCP & & \multicolumn{4}{|c|}{0.059} \\
\hline & Total & & 338 & 251 & 87 & \\
\hline
\end{tabular}

Table (4), shows the causes of failure of restorations in the whole study period. In composite restorations, loss in both groups was the main cause of failure, group I (100.0\%), and group II $(87.0 \%)$, whereas, secondary caries was the second cause of composite failure in group II (13.0\%). In group (I), no amalgam failure was recorded, while in group (II) secondary caries was the main cause of amalgam failure $(67.0 \%)$, followed by fracture $(33.0 \%)$. In both groups fracture of restorations, and secondary caries were the main causes of anterior GIC failure in both groups $(100.0 \%)$, and also in posterior GIC failure in both groups $(100.0 \%)$. Loss of retention was the main cause of SSCs failure in both groups $(100.0 \%)$.

Table (5) shows the most common factors significantly affecting the overall failure rate of restorations: unsupervised tooth brushing $(\mathrm{P}=.048, \mathrm{OR}=2.846)$, followed by failure to comply to follow up appointments $(\mathrm{P}=.021$, $\mathrm{OR}=1.388)$.

Table (4): Causes of failure in restorations in the whole study period.

\begin{tabular}{||c|c|c|c|c|c||}
\hline \multirow{2}{*}{ Restorative material } & \multirow{2}{*}{ Main cause of failure } & \multicolumn{2}{|c|}{$\begin{array}{c}\text { 6 months } \\
\text { (Group I) }\end{array}$} & \multicolumn{2}{c|}{$\begin{array}{c}12 \text { months } \\
\text { (Group II) }\end{array}$} \\
\cline { 3 - 6 } & & No & $\%$ & No & $\%$ \\
\hline \multirow{2}{*}{ Composite } & Loss & 25 & 100.0 & 20 & 87.0 \\
\cline { 2 - 6 } & Secondary caries & 0 & 0.0 & 3 & 13.0 \\
\hline \multirow{2}{*}{ Anterior GIC } & Fracture \& caries & 11 & 100.0 & 14 & $\begin{array}{c}100 \\
0\end{array}$ \\
\hline \multirow{2}{*}{ Posterior GIC } & Fracture \& caries & 2 & 100.0 & 2 & $\begin{array}{c}100 \\
0\end{array}$ \\
\hline \multirow{2}{*}{ Amalgam } & Fracture & 0 & 0 & 1 & 33.0 \\
\cline { 2 - 7 } & Secondary caries & 0 & 0 & 2 & 67.0 \\
\hline \multirow{2}{*}{ SSCs } & Loss of retention & 1 & 100.0 & 6 & 100 \\
\hline \hline
\end{tabular}

Table (5): Patient variables significantly affecting overall failure of restorations in the whole study period (logistic regression).

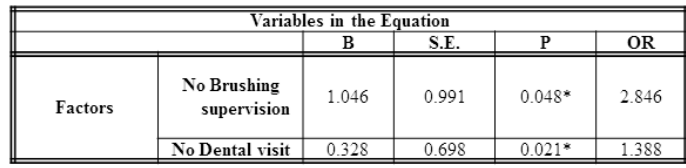

B: regression coefficient

SE: standard error

OR: Odds ratio

\section{DISCUSSION}

Comprehensive dental treatment for children with early childhood caries (ECC) under general anesthesia (GA) has greatly increased worldwide. Considering the high cost and potential risks of GA, it is necessary to minimize the risk of treatment failures. (15)Therefore, evaluation of such restorative failures seems essential.

Regarding gender distribution within this study sample there was a significant difference within the two study periods. These disproportionate number recalled patients were more of the boys. This might reflect the fact that boys mature psychologically at a slower rate and haven't acquired the skills to cope within office dental treatment (16). In agreement to the current findings, Tate et al. (11) showed that $75 \%$ of the patients who returned for follow-up were males. This finding is in contrast to previous studies where it was suggested that young patients receiving dental care under GA show no gender predilection (17).

There is an association between parental education and children's oral health. In the current study the majority of the mothers were illiterate. This lack of education of the mothers could have added a great effect on their children's behavior towards oral health and consequently on visiting the dentist regularly. It was noticed that the majority of the children in the present study didn't comply to recall 
appointments. Thus in return these measures have affected the outcome of the restorations.

Regarding oral hygiene habits, the majority of the children either after 6 , or 12 months recall period, brushed their teeth once per day. Tooth brushing, when performed was done by the parents. This means that despite the treatment under GA, parents are still not interested enough to learn the correct technique for tooth brushing. This finding adds to the importance that parents need be educated about the importance of oral hygiene and regular dental checkups.

The results of this study revealed that failure rate of composite, anterior glass ionomer, posterior glass ionomer, amalgam and SSC was $92.3 \%, 83.3 \%, 23.5 \%, 10 \%, 3.3 \%$ ) respectively in the whole study period. The highest failure rate was composite restorations $(92.3 \%)$, while the lowest one was SSC (3.3\%). This is in accordance with Tate et al. (11) who evaluated the failure rates of restorative procedures for children undergoing dental rehabilitation under general anesthesia, and reported SSCs are the most reliable restorations while composite restorations are the least durable.

The high failure rate of composite restorations is mainly due to loss of composite restoration followed by the development of secondary caries. Composite resins require longer time for placement and are technique sensitive. In addition the high failure rate of composite restoration might be due to faulty cavity design that was not beveled, thereby maintaining the aprismatic layer present on primary dentition. The disposition of the hydroxyl apatite crystals in the aprismatic layer, and amount of remaining enamel have been reported to affect the quality of the adhesion between primary enamel and composite (18).

Regarding anterior and posterior GIC restorations, in the current study, fracture of restorations, and recurrence of secondary caries were the main causes of failures. This might be due to faulty design, or type of the material used by operators (conventional GIC). The previous results were similar to Mjör et al. (19) where it was reported that the main reasons for GIC failures were secondary caries, and fractured or lost restorations. They mentioned that resin modified GICs exhibited a reduced risk of fracture approximately $50 \%$ when compared to conventional GIC.

Regarding the high success rate of SSCs in the current study is probably due to appropriate and most durable restorations for treatment of children with ECC. These findings are similar to O'Sullivan and Curzon (20) who reported that SSCs are significantly more successful than amalgam or composite restorations for patients who were treated under GA. Al Eheideb et al. (21) in their study noticed that SSCs were the most successful type of restorations (95.5\%) among children treated under GA. Another study by Alireza et al. (22) reported that SSCs represented lowest failure rates $(1.9 \%)$ in comparison with other treatments.

Loss of retention was the main cause of SSCs failure in the current study. SSC success depends mainly on the quality of the tooth preparation, selection and adjustment of an appropriate crown, and the luting cements (23). Despite careful crimping and contouring, gingival margins of SSCs are often less than perfectly adapted which may lead to leakage of cement and loss of retention.

In the current study Amalgam restoration was considered the second successful restorations after SSCs. Tate et al. (11) reported the failure rate of amalgam, and SSCs was $21 \%$, and $8 \%$ respectively, also Alireza et al. (22) found that failure rate of amalgam restoration was $7.8 \%$. Secondary caries was the main cause of amalgam failure in this study followed by fracture, this might be attributed to faulty design during cavity preparation. In accordance with our study results, Ozer et al. (24) analyzed 18 studies concerning main reasons of amalgam failure, and concluded that about half of all replacements were due to secondary caries. A study by Mjör et al. (19) reported that, $77 \%$ of failed amalgam restorations were replaced due to secondary caries $(53 \%)$, or bulk fracture $(24 \%)$.

Multiple stepwise logistic regressions were used to identify the most important factor affecting restorations failure. The first factor was unsupervised brushing $(\mathrm{OR}=2.8)$, followed by not visiting the dentist $(\mathrm{OR}=1.4)$.Supervising tooth brushing by parents or caregivers has an impact on the failure of restorations and thus the recurrence of decay after treatment under GA. Some studies have documented that the clinical outcomes for treatment of ECC are poor. In agreement to the current investigation, Sheehy et al. (8) found that $23 \%$ of children treated for ECC under GA required restorations or extractions within 6 months after the initial dental surgery. In another cohort study by Berkowitz et al. (12), 52\% of patients treated under GA required retreatment within 4-6 months after dental surgery. Both studies found that the main cause of repeated dental treatment under GA was unresponsive parents to follow up visits.

One of the limitations of this study was the small sample size due to the difficulty of communication, and refusal of the parents to bring their children for follow up. It was assumed that this behavior of the parents was due to the belief that there is no problem with their children's teeth as long as there is no pain.

Given all the above, clinical outcomes for comprehensive dental treatment under GA in children with ECC are less than optimal, therefore professional and at-home preventive measures should be taken as soon as possible to minimize relapse of treatment of ECC as well as the development of new carious lesions.

\section{CONCLUSIONS}

From results of this study, it was concluded that:

1) Stainless steel crowns were the most successful restorations whereas composite restorations were the least durable.

2) Anterior restorations had a higher failure rate than posterior restorations.

3) Loss of the filling material was the main cause of failure for composite and glass ionomer restorations, caries for 
amalgam restorations and loss retention for stainless steel crowns.

4) Factors that affected restoration failure significantly were unsupervised tooth brushing and parents not complying to regular dental visits.

\section{CONFLICT OF INTEREST}

The authors declare that they have no conflicts of interest

\section{REFERENCES}

1. Silverman J, Reggiardo P, Scott C. An Essential Health Benefit: General Anasthesia for Treatment of Early Childhood Caries. Pediatric Oral Health Research \& Policy Center. May 2012. Available at: www.aapd.org/assets/1/7/POHRPCTechBreif2.pdf.

2. Atan S, Ashley P, Gilthorpe MS, Scheer B, Mason C, Roberts G. Morbidity following dental treatment of children under intubation general anesthesia in a daystay unit. Pediatr Dent 2004; 14: 9-16.

3. Enger DJ, Mourino AP. A survey of 200 pediatric dental general anesthesia cases. J Dent Child 1985; 52:36-41.

4. Vermeulen M, Vinckier F, Vandenbroucke J. Dental general anesthesia: Clinical characteristics of 933 patients. J Dent Child 1991; 58:27-30.

5. Legault JV, Diner MH, Auger R. Dental treatment of children in a general anesthetic clinic. Review of 300 cases. Can Dent Assoc 1972; 38: 221- 4.

6. Low W, Tan S, Schwartz S. The effect of severe caries on the quality of life in young children. Pediatr Dent 1999; 21: 325- 6.

7. Acs G, Pretzer S, Ng MW, Testen RD. Parental satisfaction and patient outcomes following comprehensive dental rehabilitation in the management of early childhood caries: Surgeon general's Workshop and Conference on Children and Oral Health 2000. Available at: http://www.aapd.org/assets/1/25/Acs-2305.pdf.

8. Sheehy E, Hirayama K, Tsamtosouris A: A survey of parents whose children had full-mouth rehabilitation under general anesthesia regarding subsequent preventive dental care. Pediatr Dent 1994; 16: 362-4.

9. Eidelman E, Faibis S, Peretz B. A comparison of restorations for children with early childhood caries treated under general anesthesia or conscious sedations. Pediatr Dent 2000; 22: 33-7.

10. Holland IS, Walls AW, Wallwork MA, Murray JJ. The longevity of amalgam restorations in deciduous molars. Br Dent 1986; 161: 255-8.

11. Tate AR, Needleman HL. Failure rates of restorative procedures following dental rehabilitation under general anesthesia. Pediatr Dent 2002; 24: 69-71.

12. Berkowitz RJ, Moss M, Billings RJ, Weinstein P. Clinical outcomes for nursing caries treated using general anaesthesia. J Dent Child 1997 64:210-11.
13. American Society of Anesthesiologists. Physical Status Classification System. Available at: http://www.asahq.org/clinical/physical status.htm

14. American Academy of Pediatric Dentistry. Classifications, Consequences, and Preventive Strategies. Reference Manual 2015-2016; 37:50-52.

15. American Academy of Pediatric Dentistry. Guideline on elective use of conscious sedation, deep sedation, and general anaesthesia in pediatric dental patients. Pediatr Dent 2002; 24:79.

16. Sheller B, Williams BJ, Katrina H, Lloyd M 1 . Reasons for Repeat Dental Treatment Under General Anesthesia for the Healthy Child. Pediatric Dent 2003; 25: 546-52.

17. Bohaty B, Spencer P. Trends in dental treatment rendered under general anesthesia, 1978 to 1990 . J Clin Pediatr Dent 1992; 16: 222-4.

18. Lee JK. Restoration of primary anterior teeth: review of the literature. Pediatr Dent. 2002;24(5):506-10

19. Mjör IA, Dahl JE, Moorhead JE. Placement and replacement of restorations in primary teeth. Acta Odontol Scand 2002; 60: 25-8.

20. O'Sullivan EA, Curzon ME. The efficacy of comprehensive dental care for children under general anesthesia. Br Dent J 1991; 171: 56-8.

21. AI-Eheideb AA, Herman NG. Outcomes of dental procedures performed on children under general anesthesia. J Clin Pediatr Dent 2003; 27: 181-3.

22. Alireza E, Mahdi JS, Naghme FN, Maryam H. Evaluation of efficacy of restorative dental treatment provided under general anesthesia at hospitalized pediatric dental patients of Isfahan. Dent Res J 2012: 9: 478-82.

23. Rector JA, Mitchell RJ, Spedding RH: The influence of tooth preparation and crown manipulation on the mechanical retention of stainless steel crowns. ASDCJ Dent Child 1985; 52: 422-7.

24. Ozer L, Thylstrup A. What is known about caries in relation to restorations as a reason for replacement? A review. Adv Dent Res 1995; 9: 394-402. 